\title{
Averaged Electroencephalographic Response to Intensity Modulated Tone
}

\author{
TAKUJI OKITSU \\ Department of Otolaryngology, Tohoku University School of \\ Medicine, Sendai
}

OkITsu, T. Averaged Electroencephalographic Response to Intensity Modulated Tone. Tohoku J. exp. Med., 1974, 112 (4), 315-323 — The effect of the intensity modulated tones on the electroencephalogram was investigated in normal and hearing-impaired subjects. In all normal subjects and most cases of the conductive hearing loss, the response was not evoked by the increment by $4 \mathrm{~dB}$ from the basic tone at $20 \mathrm{~dB}$ above the subjective threshold. The size of the minimal increment which effectively evoked the response was generally smaller in the cochlear hearing loss than in the normal and the conductive hearing loss. A particular case of cochlear disorder showed the response even when the increment of $0.6 \mathrm{~dB}$ was tested. The results suggest that this method is useful for differentiating lesions in the auditory system objectively.——— evoked response; intensity modulated tone; auditory system

Recently, the averaged electroencephalographic response (AER) to sound stimuli is routinely used for evaluating the hearing in young children.

On the other hand, some authors reported that AER amplitude has a close relation to the loudness recruitment. It is well known that the recruitment phenomenon is an important factor for differentiation of the cochlear disorder from the conductive and retrocochlear disorders.

In this paper, the usefulness of the AER to intensity modulated tone for an objective measurement of the loudness recruitment is to be discussed.

\section{Methods and SubJects}

The block diagram of the equipments for this investigation is shown in Fig. 1. Intensity modulated tones for DL-test, generated from the audiometer (Rion, AA-33), were used in this experiment. A steady state pure tone was given to patients in the intensity of 20 $\mathrm{dB}$ above his subjective threshold, and a small increment in intensity was superimposed on it at every 2 sec. The size of this increment varied from 0.2 to $4 \mathrm{~dB}$. The increment had a rise decay time of $50 \mathrm{msec}$, and its total duration was $1 \mathrm{sec}$ (Fig. 1).

The average computer (Sanei, Mediac 401) was triggered by the onset of each increment and electroencephalographic responses were averaged for 50 increments.

The auditory evoked responses were recorded from the vertex of the skull with a reference electrode on the earlobe and a grounded electrode on the forehead.

The examination was carried out at either $1000 \mathrm{~Hz}, 2000 \mathrm{~Hz}$ or $4000 \mathrm{~Hz}$. In cases of unilateral impaired hearing, the intact ear was masked with white noise of an appropriate intensity level.

Nine normal subjects (13 ears) and 19 hearing-impaired subjects were examined. Most

Received for publication, October 29, 1973. 


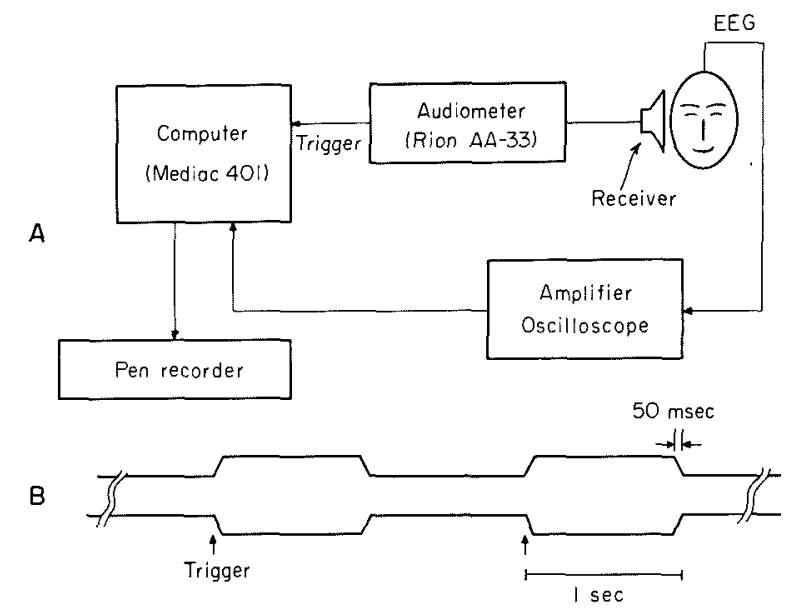

Fig. 1. Block diagram of the equipments (A) and the pattern of the tone stimuli (B).

normal cases were students, aged 19 to 21 years. The results from the normal side of the unilateral impaired cases were also treated as normal cases. Hearing-impaired subjects were composed of 11 cases of cochlear disorders (14 ears), which showed positive recruitment as revealed by SISI-test and Bekesy audiometry (Table 1), 6 cases of conductive disorders ( 8 ears) due to chronic otitis media and 2 cases of perceptive hearing loss of undifferentiated origin.

Details of the two cases of perceptive disorders were as follows. One was a 55-year-old male of a construction contractor, who had suffered from softening of the brain and aphasia. His conventional audiogram showed $\mathrm{C}_{5}$-dip which was thought to be noise induced hearing loss on account of his occupation. Although further examination for measurement of loudness recruitment could not be done, this patient was suspected of a cochlear disorder (Table 1, No. 12). The other was a male, aged 31 years, whose conventional audiogram revealed a flat curved sensorineural hearing loss of approximately 20 to $30 \mathrm{~dB}$ in both ears. Békésy audiogram showed Jerger's type III and SISI-test showed, low values on both sides. Retrocochlear lesions were suspected in this case. The AER test was performed on both sides at $2 \mathrm{KHz}$.

During the test, the subjects were laid on a bed in the soundproof and electrically

Table 1. Cochlear disordered cases

\begin{tabular}{rrrlrcc}
\hline No. $\begin{array}{c}\text { Age } \\
\text { (year) }\end{array}$ & Sex & \multicolumn{1}{c}{ Diagnosis } & Békésy type SISI-test & $\begin{array}{c}\text { Minimal increment size } \\
\text { to evoke response (dB) }\end{array}$ \\
\hline 1 & 41 & M & L. cochlear disorder & Type II & + & 1 \\
2 & 38 & M & L. cochlear disorder & II & + & 3.2 \\
3 & 36 & M & R. cochlear disorder & II & $/$ & 3.0 \\
4 & 24 & M & Noise induced hearing loss & II & $/$ & 3.0 \\
5 & 56 & F & Bilat. cochlear disorder & II & + & R. 4.0 L. 4.0 \\
6 & 30 & M & Bilat. sudden hearing loss & II & + & R. 3.6 L. 3.0 \\
7 & 49 & M & Noise induced hearing loss & II & + & R. 3.0 L. 0.6 \\
8 & 38 & M & Bilat. cochlear disorder & II & + & R. 4.0 L. 4.0 \\
9 & 30 & M & L. sudden hearing loss & II & + & 3.0 \\
10 & 55 & M & Bilat. cochlear disorder & $/$ & + & 4.0 \\
11 & 64 & M & Presbyacusis & $/$ & + & No response \\
12 & 55 & M & Aphasia (C)-dip) & Impossible Impossible & L. 2.0 \\
\hline
\end{tabular}


shielded room. The tone stimuli were given to the subjects through a receiver. The minimal size of increment that caused the evoked responses was measured at $20 \mathrm{~dB}$ above the subjective threshold. In some of the normal cases, the AER to the intensity modulated tone was also investigated at $50 \mathrm{~dB}$ above the subjective threshold.

\section{Results}

1. Wave-form of the evoked response

A wave-form of the averaged evoked response to the intensity modulated tones was fundamentally the same as that to tone pips (Figs. 4 and 5). Each of $\mathrm{P}_{1}, \mathrm{~N}_{1}$ and $\mathrm{P}_{2}$ components had a detectable peak, but $\mathrm{N}_{1}$ often showed double peaks or a trapezoid shaped peak (Fig. 3). The amplitude of response to the intensity modulated tone was generally smaller and the latency tended to be longer as compared with the responses to tone pips. However, some cases of the cochlear disorder showed very large and clear responses (Fig. 5).

2. Minimal increment size of tone intensity to evoke the response (Fig. 6)

Normal subjects: In all normal subjects, the evoked responses were not detected even with $4 \mathrm{~dB}$ increment at $20 \mathrm{~dB}$ above the subjective threshold (Fig. 2). But the threshold of the AER was lowered when the intensity increment was superposed on a steady tone stronger than $20 \mathrm{~dB}$ (Fig. 3).

Conductive disorders: No response was evoked by $4 \mathrm{~dB}$ increment in all conductive hearing losses except for one case (Fig. 7).

Cochlear disorders: The minimal increment size in the cochlear disorders was generally smaller than in the normal and conductive hearing-impaired subjects. Some of the cochlear disordered cases showed prominent evoked responses and one particular case showed the response even to $0.6 \mathrm{~dB}$ increment (Fig. 5).

Perceptive disorders: The evoked response was not elicited even by $4 \mathrm{~dB}$ in-

Fig. 2. AER to intensity modulated tone in a 20 -year-old normal subject at $20 \mathrm{~dB}$ above her subjective threshold. No response is elicited even by $4 \mathrm{~dB}$ increment. This figure shows the curves of two trials. $(-)$ : no response.

\section{$2000 \mathrm{~Hz}$}
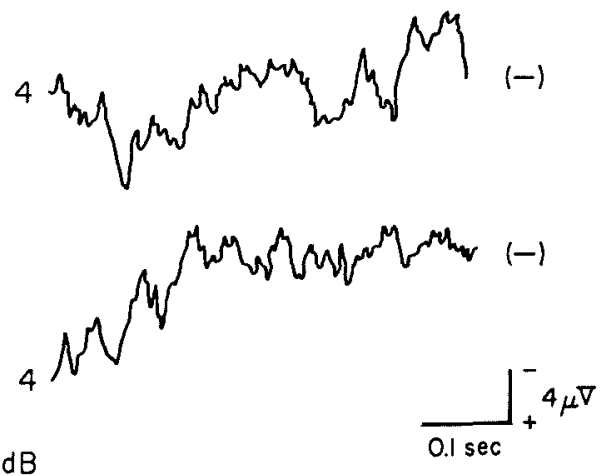


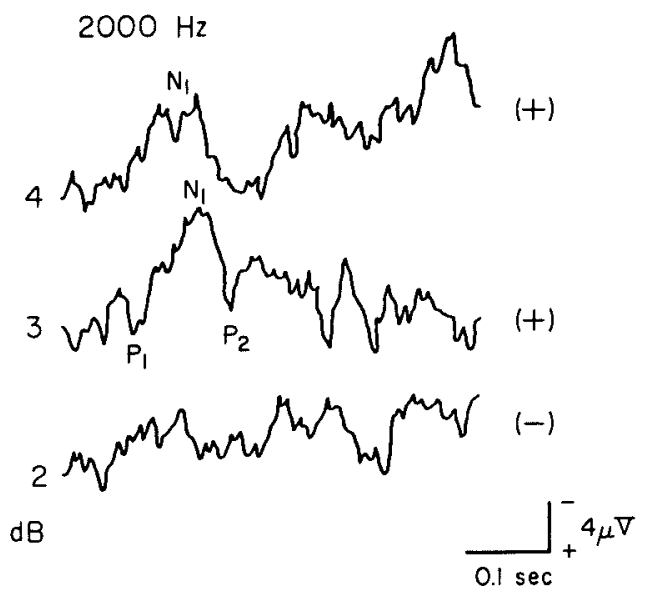

Fig. 3. AER of the same subject as Fig. 2, obtained at $50 \mathrm{~dB}$ above her subjective threshold. The response is evoked by as little as $3 \mathrm{~dB}$ increment. $(+)$ : positive response.
Fig. 4. AER from a patient with cochlear disorder at $20 \mathrm{~dB}$ above the threshold. The evoked response is detected at $3.6 \mathrm{~dB}$ inerement. Case No.6 in Table 1.

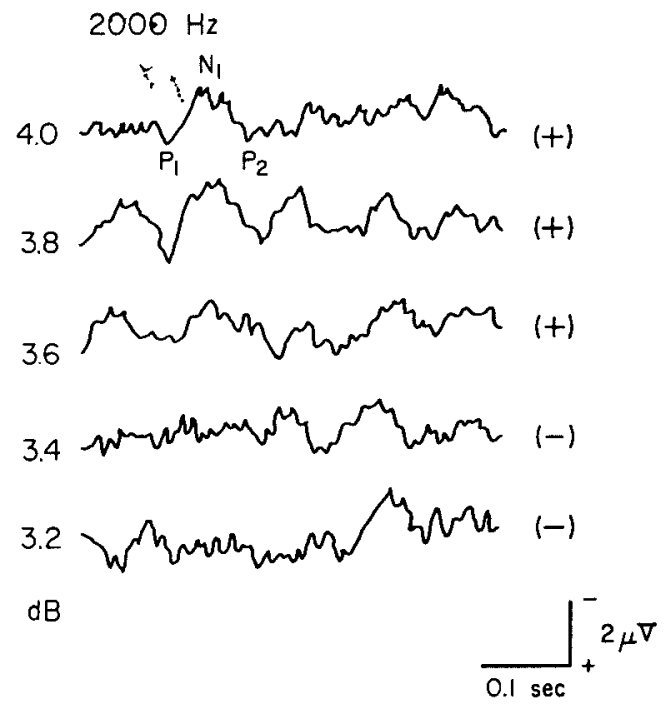

crement in the case suspected of retrocochlear lesions (Fig. 8). In contrast, the case suspected of cochlear disorder (Table 1, No. 12) showed the response to $2 \mathrm{~dB}$ increment at $4 \mathrm{KHz}$ (Fig. 9).

\section{Discussion}

It has been well known that the amplitude of the acoustically evoked response becomes larger with an increase in intensity of tone stimuli. Keidel and Spreng 
Fig. 5. AER from a particular case of cochlear disorder at $20 \mathrm{~dB}$ above the threshold. A large response is showed at $0.6 \mathrm{~dB}$ increment. Case No. 7 in Table 1 .
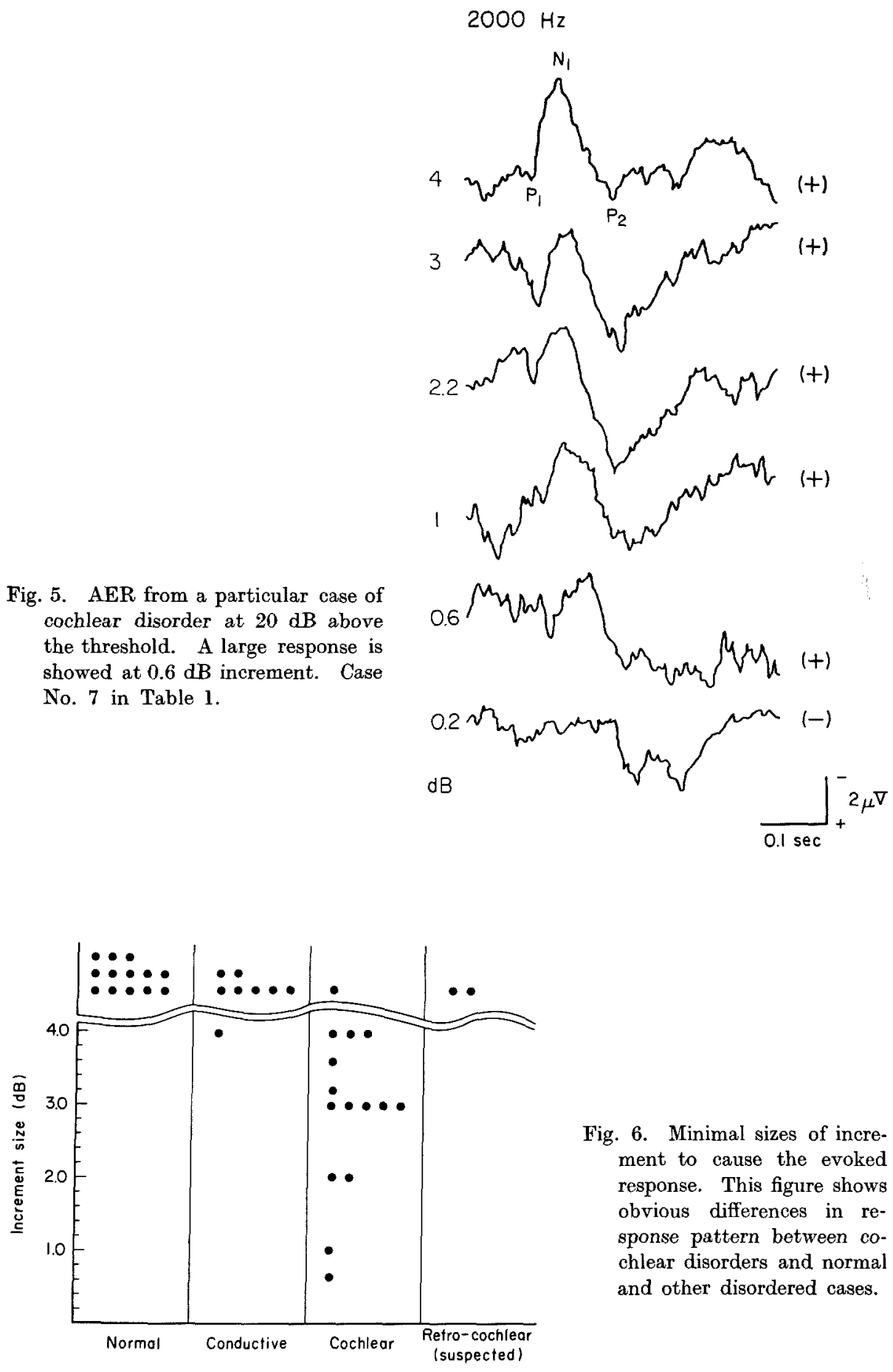

Fig. 6. Minimal sizes of increment to cause the evoked response. This figure shows obvious differences in response pattern between cochlear disorders and normal and other disordered cases. 


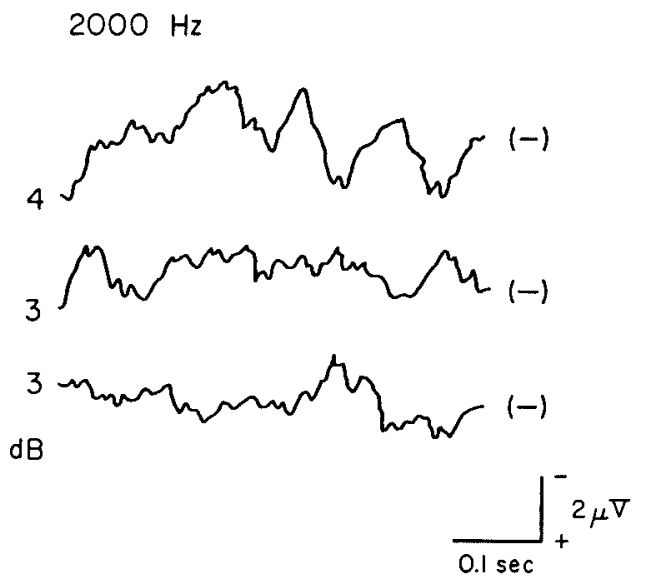

Fig. 7. AER at $20 \mathrm{~dB}$ above the subjective threshold obtained from a patient, aged 30 years, with conductive disorders due to chronic otitis media. The evoked response was not detected.

Fig. 8. AER at $20 \mathrm{~dB}$ above the subjective threshold obtained from a case, aged 31 years, suspected of retrocochlear disorder. No evoked response was elicited by intensity modulated tones in three trials.

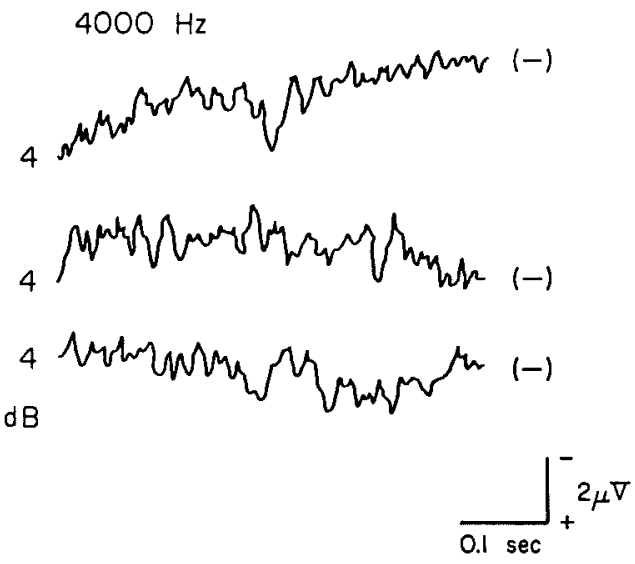

(1965) described in their psychophysical study that the human cortical responses to acoustic stimuli, occurring within 150 to $170 \mathrm{msec}$ after stimulus onset, yielded input-output functions fairly comparable with Stevens' power functions. It is surmised therefore that the amplitude of the evoked response to acoustic stimuli may closely be related to loudness growth. In order to differentiate the hearing disorders, some studies have been done for several years, in which normal and impaired subjects were compared for the intensity-function curve and amplitude or latency of the evoked responses (Knight and Beagley 1969; Townsend and Cody 1970; Kollár 1971). Previously, as Cody et al. (1968) described, the author also found that, in unilateral cochlear disorders, the threshold of AER of the impaired 
Fig. 9. AER at $20 \mathrm{~dB}$ above the subjective threshold in a case suspected of cochlear disorder, Case No. 12 in Table 1. This case showed the response to as little as $2 \mathrm{~dB}$ increment at $4 \mathrm{KHz}$.
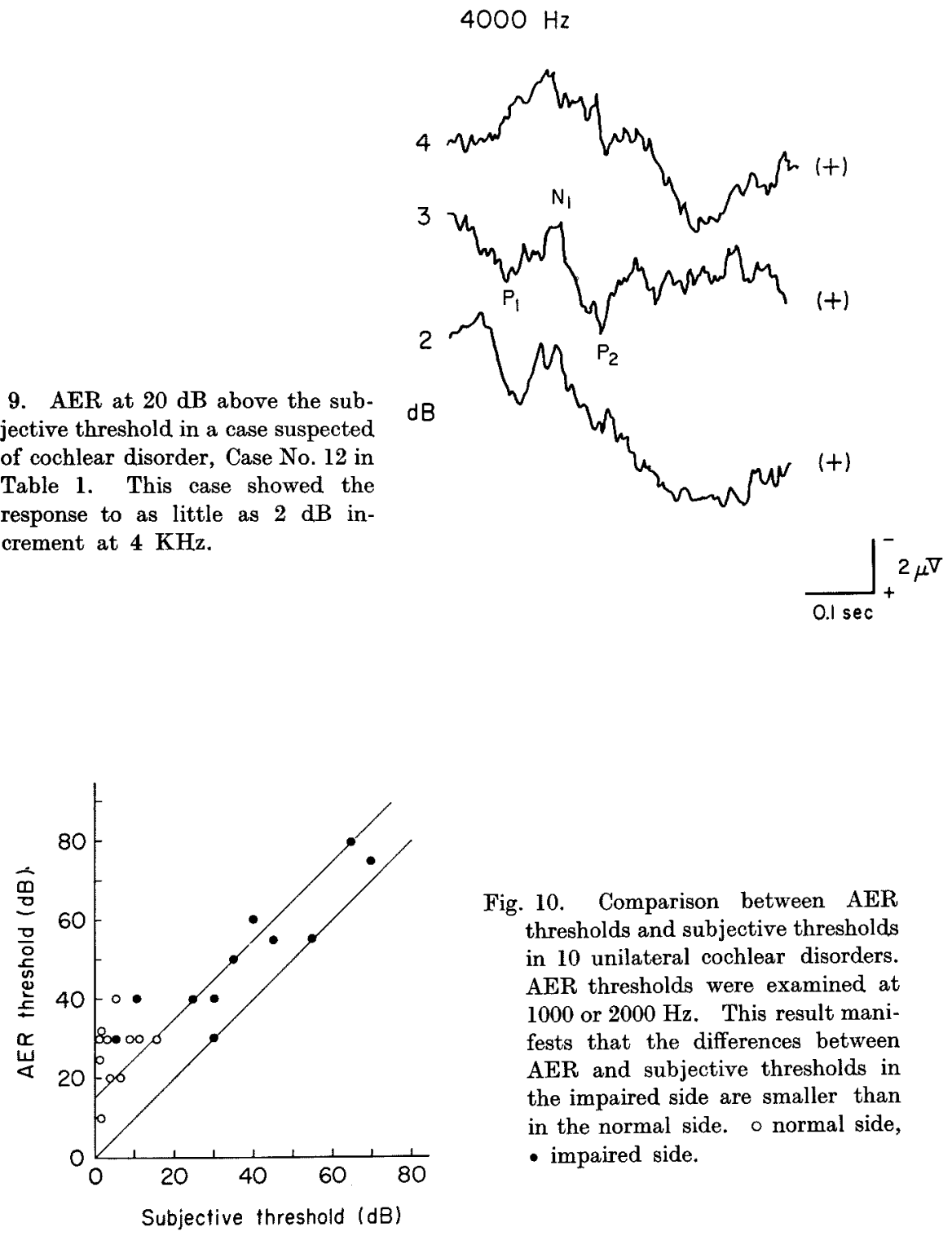

Fig. 10. Comparison between AER thresholds and subjective thresholds in 10 unilateral cochlear disorders. AER thresholds were examined at 1000 or $2000 \mathrm{~Hz}$. This result manifests that the differences between AER and subjective thresholds in the impaired side are smaller than in the normal side. o normal side, - impaired side.

side was closer to the conventional threshold than that of the normal side (Fig. 10).

But these data also suggested that it was difficult to make a differential diagnosis among hearing disorders by means of AER examinations, because there was overlapping of the results between normal and hearing-impaired groups. Spoor et al. (1969) reported the relation between the $N_{1}$-peak latency and the $N_{1}-P_{2}$ peak to peak voltage of the evoked auditory responses elicited by intensity modulated 
tones in three normal subjects. They detected the response to $1 \mathrm{~dB}$ increment at $70 \mathrm{~dB}$ above the subjective threshold and to $3 \mathrm{~dB}$ increment at $30 \mathrm{~dB}$ above the subjective threshold.

The author also demonstrated a similar phenomenon. Namely, in the normal subjects, the evoked response was not elicited even by $4 \mathrm{~dB}$ increment at $20 \mathrm{~dB}$ above the subjective threshold, but the response was elicited by as small as $3 \mathrm{~dB}$ increment when it was made at $50 \mathrm{~dB}$ above the subjective threshold (Figs. 2 and 3). The higher is the level in tone intensity at which the increment is made, is the smaller the minimal size of the increment to evoke the response.

On the other hand, Jerger and Jerger (1970) compared amplitude of the averaged electroencephalic response to the intensity and frequency changes with results of behavioral performance (percent of SISI-test) in a normal and a sensorineural hearing-impaired subject. Their experiments evidently showed a close correspondence between the results of SISI-test and the amplitude of the averaged evoked response to the intensity change. In addition, Kollár and Röser (1971) demonstrated using ERA that all patients with perceptive hearing losses reacted to an increase in intensity of as small as $1 \mathrm{~dB}$ at $40 \mathrm{~dB}$ above the threshold.

The present results indicated that the cochlear disorders reacted to a smaller increment than the normal subjects as well as than the patients with conductive or retrocochlear impairments. Namely, the evoked responses in most cochlear disordered cases were detected with an increment less than $4 \mathrm{~dB}$ and some of them showed a large and clear response even to that less than $2.0 \mathrm{~dB}$ (Figs. 5 and 6). In normal subjects and patients with other types of hearing impairment, however, the response was not evoked by $4 \mathrm{~dB}$ increment at $20 \mathrm{~dB}$ above the subjective threshold (Fig. 6).

From these results, it is noticed that there are apparent differences in response pattern between cochlear and other types of disorders. It seems likely that this phenomenon closely relates to the loudness recruitment. The lesions in the auditory system can be diagnosed satisfactorily by AER to an intensity modulated tone made at $20 \mathrm{~dB}$ above the subjective threshold as described above.

This investigation does suggest that the present method is useful for differentiating lesions in the auditory system objectively. Especially, this method seems to be useful for measuring the loudness recruitment in younger children and noncooperative adults. Moreover, this method has an advantage of use of tone stimuli for DL-test generated from an audiometer, not requiring any other special stimulus tone generators.

\section{Acknowledgment}

I express my graditude to Professor Kazutomo Kawamoto for reading the manuscript and to Dr. Tamotsu Miyoshi for his advice and encouragement during this work.

\section{References}

1) Cody, D.T.R., Griffing, T. \& Taylor, W. (1968) Assessment of the newer tests of auditory function. Ann. Otol. (St. Louis), 77, 686-705. 
2) Jerger, J. \& Jerger, S. (1970) Evoked response to intensity and frequency change. Arch. Otolaryng., 91, 433-436.

3) Keidel, W.D. \& Spreng, M. (1965) Neurophysiological evidence for the Stevens power function in man. J. acoust. Soc. Amer., 38, 191-195.

4) Knight, J.J. \& Beagley, H.A. (1969) Auditory evoked response and loudness function. Int. Audiology, 8, 382-386.

5) Kollár, A. (1971) Diagnose der Innenohrschwerhörigkeit mit evozierten Hirnpotentialen (ERA). Mschr. Ohrenheilk., 150, 101-106.

6) Kollár, A. \& Röser, D. (1971) Objektivierung des Recruitments mittels Electric Response Audiometry (ERA). Z. Laryng. Rhinol., 50, 365-369.

7) Spoor, A., Timmer, F. \& Odenthal, D.W. (1969) The evoked auditory response (ERA) to intensity modulated and frequency modulated tones and tone bursts. Int. Audiology, 8, 410-415.

8) Townsend, G.L. \& Cody, D.T.R. (1970) Vertex response: Influence of lesions in the auditory system. Laryngoscope (St. Louis), 80, 979-999. 